\title{
ПОЛУЧЕНИЕ МОДИФИЦИРОВАННЫХ НИТРАМИНОВ ДЛЯ ПРИМЕНЕНИЯ В НЕЭЛЕКТРИЧЕСКИХ СИСТЕМАХ ИНИЦИИРОВАНИЯ
}

\author{
М. М. Челтонов ${ }^{1 *}$, \\ к.m.н. С. А. Опарин ${ }^{2}$, \\ к.т.н. Е. Ю. Нестерова ${ }^{3}$, \\ к.т.н. А. Л. Кириченко ${ }^{\prime}$, \\ д.т.н. Е. Б. Устименко
}

${ }^{1}$ Государственное предприятие «Научно-производственное объединение «Павлоградский химический завод», г. Павлоград, Украина;

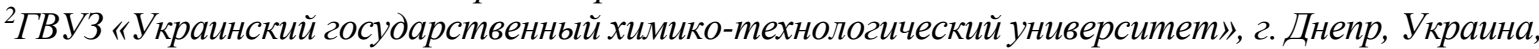

${ }^{3}$ ГВУЗ «Днепровский национальный университет имени Олеся Гончара», г. Днепр, Украина

\section{DOI: https://doi.org/10.31435/rsglobal_ws/31102019/6716}

\section{ARTICLE INFO}

Received: 10 August 2019

Accepted: 09 October 2019

Published: 31 October 2019

\section{KEYWORDS}

solid propellants,

crystallization,

octogen,

non-electric initiation systems,

dimethyl sulphoxide.

\begin{abstract}
In present-day conditions of Ukraine the setup of domestic production of non-electric initiation systems (NEIS) is an important issue. The main component of NEIS consisting of mixture of nitramine (octogen or hexogen) and aluminum. The deficiency of the above nitramines may be solved through applying the resource-recovery technologies of disposal of solid propellant (SP) and ammunition, which are further unusable as intended. However, when applying the mentioned technologies, the nitramine extracted from solid propellant and ammunition does not conform to the requirements on quality of commercial product for NEIS production. The purpose of this research is to obtain nitramine extracted from solid propellants by crystallization in dimethyl sulphoxide (DMSO) aqueous solution to obtain a product usable in manufacturing NEIS shock tubes.
\end{abstract}

Citation: М. М. Челтонов, С. А. Опарин, Е. Ю. Нестерова, А. Л. Кириченко, Е. Б. Устименко. (2019) Poluchenie Modificirovannyh Nitraminov dlya Primeneniya v Neelektricheskih Sistemah Iniciirovaniya. World Science. 10(50), Vol.1. doi: 10.31435/rsglobal_ws/31102019/6716

Copyright: (c) 2019 М. М. Челтонов, С. А. Опарин, Е. Ю. Нестерова, А. Л. Кириченко, Е. Б. Устименко. This is an open-access article distributed under the terms of the Creative Commons Attribution License (CC BY). The use, distribution or reproduction in other forums is permitted, provided the original author(s) or licensor are credited and that the original publication in this journal is cited, in accordance with accepted academic practice. No use, distribution or reproduction is permitted which does not comply with these terms.

Введение. В настоящее время на Украине при проведении взрывных работ [1], для создания разных схем взрывания зарядов промышленных взрывчатых веществ (BВ), используют неэлектрические системы инициирования (НСИ). высокая безопасность в обращении и возможность создания схем взрывания различной сложности обуславливает эффективность их применения.

НСИ предназначена для инициирования промежуточных детонаторов и патроновбоевиков при ведении взрывных работ как на дневной поверхности, так и в забоях подземных выработок - в рудниках и шахтах), при строительстве тоннелей, а также для взрывания под водой. Основным компонентом, входящего в состав НСИ, является нитрамин (октоген или гексоген). Уменьшение дефицита необходимых компонентов НСИ, возможно за счёт использования нитраминов, извлеченных из ТРТ и БП с истёкшим сроком хранения. Однако, технология утилизации ТРТ и боеприпасов в которой предусмотрено получение таких компонентов с заданными характеристиками в настоящее время полностью не отработана. 
Одной из проблем, требующих решения, является получение вторичного сырья (нитраминов) с соответствующими параметрами. Применяемый в составе НСИ октоген (нитрамин) должен иметь кристаллы моноклинной орторомбической $\beta$-формы с размером частиц 10 - 25 мкм.

Целью настоящих исследований является получение нитрамина, извлечённого из ТРТ, методом кристаллизации в водном растворе диметилсульфоксида, пригодного для использования в волноводах НСИ.

\section{Экспериментальная часть.}

Исходный нитрамин был извлечён из полимерной крошки ТРТ с применением ДМСО и исследован на термическую стабильность с применением дифференциально-термического анализа (ДТА) на дифференциально-термическом анализаторе L81 Lenseis.

Для сравнения с литературными данными и оценки растворимости исходный нитрамин растворяли в ДМСО следующим образом: навеску нитрамина с пределом взвешивания 0,01 г, растворяли в ДМСО при перемешивании на магнитной мешалке в интервале температур 20 - 70 ${ }^{\circ} \mathrm{C}$. Не растворившийся нитрамин отфильтровывали, промывали на фильтре этилацетатом, высушивали при температуре 20 - $25^{\circ} \mathrm{C}$ до постоянного веса и взвешивали.

Далее была выполнена модификация кристаллов нитрамина следующим образом: готовили $20-40 \%$ раствор нитрамина в диметилсульфоксиде (ДМСО). После фильтрования от нерастворённых механических примесей в полученный раствор при перемешивании механической мешалкой различной конструкции (стеклянной лопастной, медной в форме спирали, лопастной из нержавеющей стали, пропеллерной) добавили воду с температурой $5^{\circ} \mathrm{C}$. После перемешивания выпавший нитрамин отфильтровали, сушили и взвешивали.

Размер и форма кристаллов модифицированного нитрамина контролировался под микроскопом Leica DMILM.

Результаты и их обсуждение. Из данных приведенных на рис. 1-2 следует, что нитрамин, извлеченный из полимерной крошки ТРТ (диапазон разложения $278,4-289,6^{\circ} \mathrm{C}$ ) имеет сходные теплофизические параметры с товарным нитрамином (диапазон разложения $275,9-290,3{ }^{\circ} \mathrm{C}$ ).

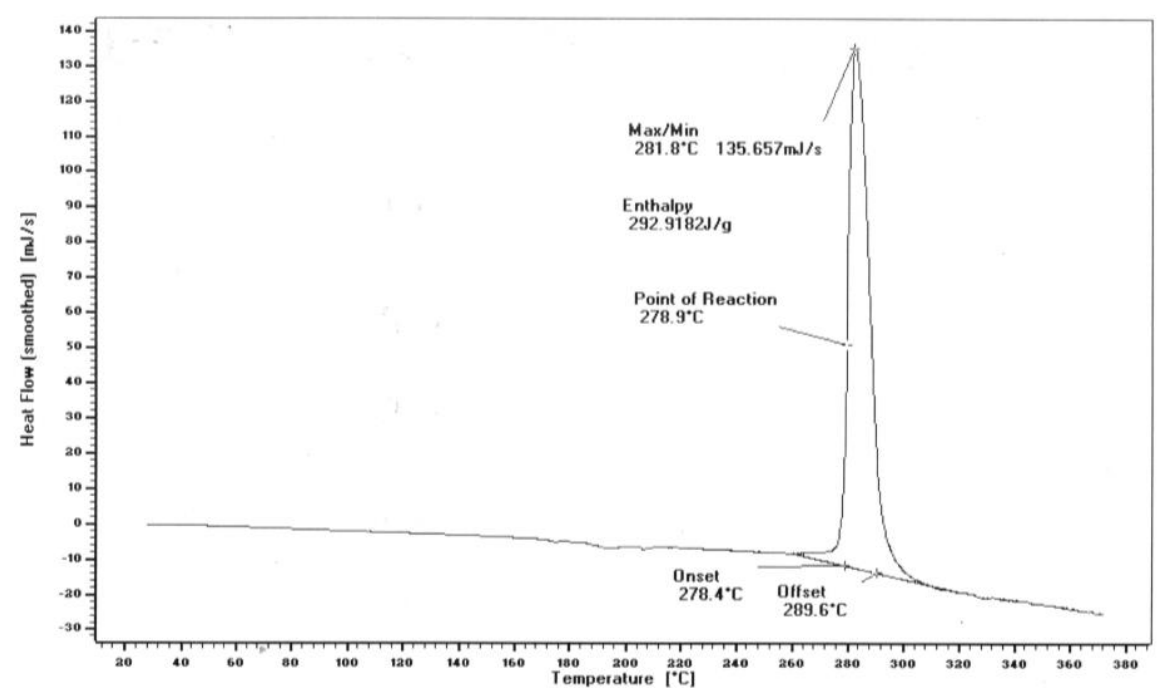

Рис. 1. Термограмма ДТА извлечённого нитрамина (скорость нагрева $10^{\circ} \mathrm{C} /$ мин)

Нитрамин, извлеченный из полимерной крошки ТРТ, подвергался модификации кристаллизации в органическом растворителе диметилсульфоксиде [2-3].

В результате проведенных работ была отработана методика получения нитрамина моноклинной орторомбической $\beta$-формы с размером частиц 10 - 25 мкм, которая состоит в следующем: нитрамин, извлечённый из ТРТ, растворяли в ДМСО в соотношении $1: 4$. После фильтрования от механических примесей, в раствор нитрамина в ДМСО при перемешивании (частота вращения мешалки $25-30 \mathrm{c}^{-1}$ ) добавляли воду в следующем соотношении вода : ДМСО - $1: 1,3$. Воду добавляли 2 порциями с температурой $5{ }^{\circ} \mathrm{C}, 1$ порция воды составляла $\sim 3 / 4$ от общего объёма, затем перемешивали 5 - 10 мин и добавляли 2 порцию воды $\sim 1 / 4$ от общего объёма, перемешивали 0,5 - 2 мин, отфильтровывали, сушили, взвешивали модифицированный нитрамин. 


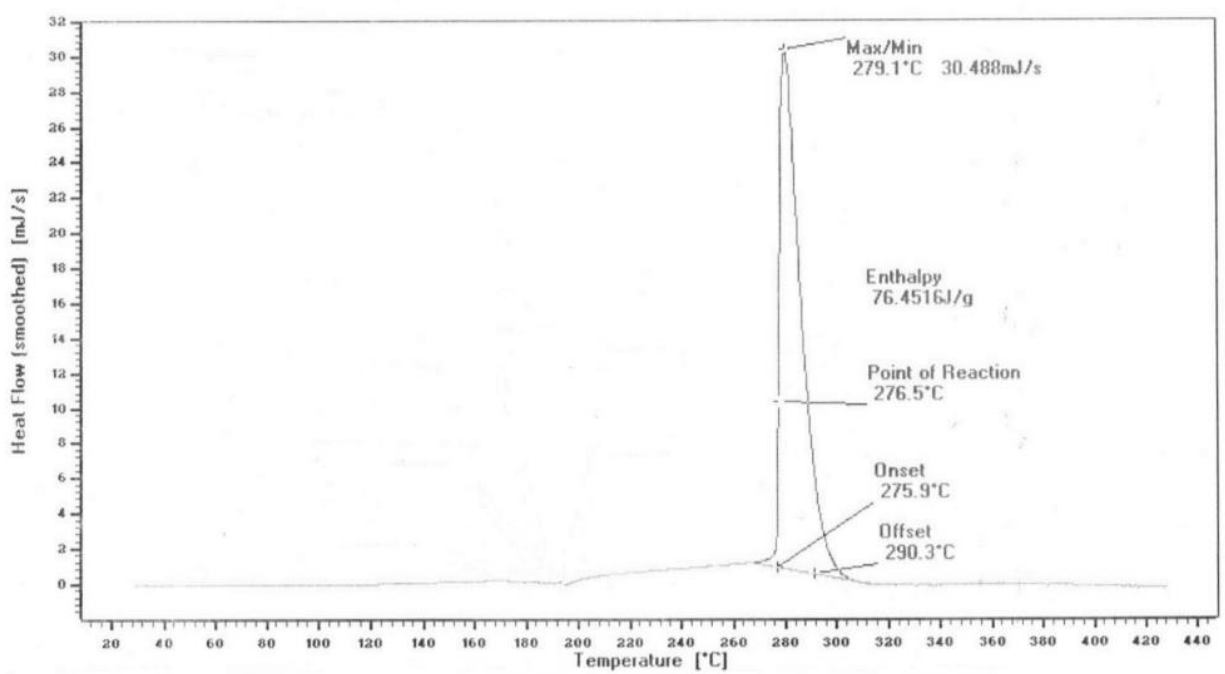

Рис. 2. Термограмма ДТА товарного нитрамина (скорость нагрева $10^{\circ} \mathrm{C} /$ мин)

Изготовленные опытные партии волноводов неэлектрических систем инициирования с использованием извлечённого и модифицированного нитрамина соответствуют требованиям ТУ У 24.6-14310112-043-2005 [4] на неэлектрические системы инициирования (табл. 1).

Таблица 1. Характеристики изготовленных волноводов неэлектрических систем инициирования на соответствие требованиям ТУ У 24.6-14310112-043-2005

\begin{tabular}{|c|c|c|}
\hline Наименование показателя & $\begin{array}{c}\text { Требование } \\
\text { ТУ У 24.6-14310112-043- } \\
2005\end{array}$ & Фактический результат \\
\hline Скорость ударной волны волновода, м/с & $1900 \pm 200$ & $1729-1824$ \\
\hline $\begin{array}{c}\text { Предельное удлинение волновода, при } \\
\text { котором сохраняется передача } \\
\text { детонации, после воздействия } \\
\text { температуры минус } 35 \pm 5^{\circ} \mathrm{C} \text { и плюс } 85 \pm 5 \\
{ }^{\circ} \mathrm{C}, \%\end{array}$ & $\geq 200$ & 200 \\
\hline $\begin{array}{c}\text { Эластичность волновода после } \\
\text { воздействия температуры минус } 35 \pm 5{ }^{\circ} \mathrm{C} \\
\text { и плюс } 85 \pm 5^{\circ} \mathrm{C} \text {, раз }\end{array}$ & $\geq 5$ & 5 \\
\hline $\begin{array}{c}\text { Восприимчивость к инициирующему } \\
\text { импульсу от электродетонатора, } \\
\text { стандартного капсюля-детонатора, } \\
\text { детонирующего шнура с навеской не } \\
\text { менее } 6 \text { г/м, искроразрядного устройства }\end{array}$ & Полная & Полная \\
\hline
\end{tabular}

Согласно табл. 1 волноводы НСИ, изготовленные на основе модифицированного нитрамина соответствуют требованиям НД по: скорости ударной волны, предельному удлинению волновода при котором сохраняется передача детонации, эластичности волновода и восприимчивость к инициирующему импульсу. Таким образом в настоящей работе получены исходные данные для разработки регламента технологического процесса производства волноводов неэлектрических систем инициирования для серийного производства.

Выводы. Получен модифицированный нитрамин с характеристиками, удовлетворяющими требования нормативной документации на нитрамин, применяемый для НСИ.

Из модифицированного нитрамина было изготовлены опытные партии волноводов НСИ, которые соответствовали требованиям нормативной документации. Получены исходные данные для разработки методики модификации нитрамина и регламента технологического процесса производства волноводов СИН для серийного производства на его основе. 


\section{ЛИТЕРАТУРА}

1. Безопасность процессов производства и применения эмульсионных взрывчатых веществ с компонентами утилизируемых вооружений. Монография // Шиман Л.Н., Устименко Е.Б., Голинько В.И., Соболев В.В. - Днепропетровск: «ЛИРА», 2013.-526 с.

2. Ломовцева Г.А., Веселова Е.В., Збарский В.Л., Юдин Н.В. О некоторых особенностях растворимости циклических нитраминов в органических растворителях./ Успехи в химии и химической технологии: сб. научных трудов, Т. XXVI, № 3 (132). - М.: РХТУ им. Д. И. Менделеева. - 2012. - С. 21-25.

3. Kim K.J., Kim H.S., Sim J.S. Solubilities of Octahydro-1,3,5,7-tetranitro-1,3,5,7-tetrazocine in $\gamma$ Butyrolactone + Water, Dimethylsulfoxide + Water, and N-Methyl pyrrolidone + Water. Journal of Chemical \& Engineering Data, 2013, vol. 58 (9), pp. 2410-2413, DOI: 10.1021/je400199m.

4. ТУ У 24.6-14310112-043-2005 Система инициирования взрывчатых материалов неэлектрическая Прима-Эра. - Павлоград, ГП «НПО «ПХЗ», 2007 - 63 с. 